\title{
QUALIDADE DAS ÁGUAS DO CÓRREGO BANDEIRANTES NA SUB-BACIA DO RIBEIRÃO CLARO, MUNICÍPIO DE RIO CLARO, SP, BRASIL
}

\author{
WATER QUALITY BANDEIRANTES STREAM IN SUB- \\ BASIN RIBEIRÃO CLARO, RIO CLARO, SP, BRAZIL
}

\section{Eleni Nadai Malagutti; Sâmia Maria Tauk-Tornisielo}

Centro de Estudos Ambientais, Universidade Estadual Paulista. Avenida 24-A, 1515, Bairro Bela Vista, CEP 13506-900. Rio Claro, SP, Brasil. E-mail seb@rc.unesp.br

\begin{abstract}
RESUMO
O Ribeirão Claro é um importante afluente do rio Corumbataí e parte dele está dentro da área urbana de Rio Claro, SP e possui uma das Estações de Tratamento de Água (ETA) desse município. O córrego Bandeirantes é um de seus afluentes e totalmente urbano, sujeito diretamente o uso e ocupação do solo em toda sua extensão. Já houve estudo de sua qualidade de água em 2002, mas recentemente com a construção de emissário ao longo do Ribeirão Claro e do Fórum em suas margens houve interesse de se obter informações sobre a qualidade da água, de forma a associa -las com outros fatores presentes na microbacia. Muitos fatores determinados não estiveram dentro do que determina a Resolução 357;05, para rio de classe 2. Há indícios que a qualidade da água deste córrego vem piorando, como também a quantidade por falta de conservação de suas margens e da mata ciliar.
\end{abstract}

Palavras-chave: Poluição das Águas. Fatores Bióticos. Fatores Abióticos. Metais Pesados. Indice de Qualidade das Águas.

\footnotetext{
ABSTRACT

The Ribeirão Claro is an important tributary of the river Corumbataí and part of it is within the urban area of Rio Claro, SP and has one of the stations of water treatment plant (WTP) of this municipality. The Bandeirantes stream is one of its tributaries and totally urban, directly subject to the use and occupation of land along its entire length. There have been studying its water quality in 2002, but recently with the construction of outfall along the Ribeirão Claro and the Forum on its banks was of interest to obtain information about water quality in order to associate them with other factors present in the watershed. Many factors have not been determined in the determining the Resolution 357/05 for class 2 river There is evidence that the water quality of this stream has been worsening, as well as the amount due to lack of conservation of its banks and riparian vegetation.

Keywords: Pollution of Water. Biotic Factors. Abiotic Factors. Heavy Metals. Water Quality Index.
} 


\section{INTRODUÇÃO}

A bacia hidrográfica é a unidade da paisagem que melhor se ajusta ao objetivo do planejamento, este importante instrumento para orientar o desenvolvimento de uma região. A problemática dessa unidade só poderá ser equacionada com um diagnóstico ambiental adequado, no qual estão inseridos os fatores biológicos, físicos e antrópicos, de forma integrada (WALLING e GREGORY, 1973).

O Programa Estadual de Microbacias do Estado de São Paulo (1993) afirmou que a unidade microbacia é utilizada como polo de irradiação de desenvolvimento para o resto da região. Além disso, geralmente, a situação social existente na microbacia reflete o que acontece no resto da cidade (CERRI, 1999).

Cada pessoa possui sua própria concepção de ambiente, mas esta pode pode ser comum, tanto nas imagens quanto na conduta. Pode também surgir expectativas compartilhadas pela população que, se orientadas por políticas publicas podem nortear a ação e gerar impactos positivos no desenvolvimento econômico ou sociocultural da comunidade. Alterar a qualidade da água significa prejudicar a vida do homem e de outros seres vivos que dela dependem. A água na natureza é um meio vivente, portador de elementos benéficos que contribuem para a sua qualidade. Contaminando-a ou a poluindo corre-se o risco de destruir os seres vivos e de modo desfavorável e irreversível todo o ecossistema onde está inserida. Toda diminuição importante da qualidade ou da quantidade de água corrente ou represada corre o risco de tornar-se nociva para o homem e para os outros seres vivos (DERISIO, 1992).

O monitoramento da qualidade requer a avaliação integrada, sendo as amostras submetidas a exames laboratoriais utilizando-se fatores internacionais elaborados pela Organização Mundial da Saúde (OMS) e aceitos pelo Ministério da Saúde, com algumas restrições quanto a valores máximos permitidos (RICHTER e NETTO, 1991). Para o monitoramento e caracterização da qualidade das águas, os fatores físicos, químicos e microbiológicos são selecionados e também para gerar informações sobre os compartimentos espaciais do recurso hídrico e seus comportamentos temporais obtidos a cada coleta de campo.

A partir de um estudo realizado em 1970 pela "National Sanitation Foundation" dos Estados Unidos, a CETESB adaptou e desenvolveu o IQA - Índice de Qualidade das Águas que incorpora nove variáveis consideradas relevantes para a avaliação da qualidade das águas, tendo como determinante principal a sua utilização para abastecimento público. A criação do IQA baseou-se numa pesquisa de opinião junto a especialistas em qualidade de águas, que indicaram as variáveis a serem avaliadas, o peso relativo e a condição com que se apresentam cada fator, segundo uma escala de valores "rating". O IQA incorpora nove fatores considerados relevantes para avaliação da qualidade das águas: temperatura, $\mathrm{pH}$, oxigênio dissolvido, demanda bioquímica de oxigênio, coliformes termotolerantes $(E$. coli), nitrogênio total, fósforo sólidos (resíduos) totais e turbidez. A fórmula utilizada para o calculo do IQA é a seguinte (CETESB, 2009).

Uma das bacias melhor estudadas é a do rio Corumbataí situada na região centro oeste do Estado de São Paulo, entre os paralelos $22^{\circ} 04^{\prime} 46^{\prime \prime}$ e $22^{\circ} 26^{\prime \prime} 23^{\prime \prime}$ e $47^{\circ} 56^{\prime} 15^{\prime \prime}$, correspondendo a uma superficie de aproximadamente $1710 \mathrm{~km}^{2}$. Os principais afluentes do rio Corumbataí são os rios: Cabeça, Passa-Cinco e Ribeirão Claro, drenando o setor do território paulista situado entre as "cuestas" arenito basálticas do planalto ocidental paulista, na seção centro-ocidental (VALENTE, 2001).

A bacia do rio Corumbataí sofre expressivos impactos ambientais negativos: lançamento de esgoto residenciais e efluentes industriais, ocacionando poluição nos corpos de água superficiais e subterrâneos; disposição inadequada dos resíduos sólidos; crescimento desordenado das áreas urbanas; erosão e assoreamento devido à retirada das matas ciliares; atividades mineradoras; manejo 
inadequado das áreas agrícolas; e, exploração intensiva de monoculturas em especial à cultura de cana-de-açúcar (PALMA-SILVA e TAUK-TORNISIELO, 2001).

Uma das microbacias da bacia do rio Corumbataí é a do Ribeirão Claro. Esta microbacia possui $13,98 \mathrm{~km}$ de largura por $34,04 \mathrm{~km}$ de comprimento, perfazendo uma área de $270,0 \mathrm{~km}^{2}$ dentro dos municípios de Corumbataí, Rio Claro, Araras e Santa Gertrudes. O Ribeirão Claro possui como afluentes, no seu alto curso, os Córregos Jacu e o da Fazenda Angélica, ambos à margem direita. No médio curso, na margem esquerda, recebe águas dos Córregos Cachoeirinha e Bandeirantes, além dos Córregos Ibitinga e Santo Antônio na margem direita. Por fim, no baixo curso, os Córregos do Barreiro e o da Fazenda Itaqui desembocam no Ribeirão Claro, que por sua vez, tem sua foz no rio Corumbataí (FONSECA, 2008).

O Ribeirão Claro nasce na zona rural do município de Corumbataí e atravessa áreas como as rurais com pastagem e cultivo de cana-de-açúcar, a Floresta Estadual Edmundo Navarro de Andrade (FEENA) e a parte leste da zona urbana de Rio Claro, onde recebe efluentes domésticos e industriais. Há diversos pontos de captação de água neste recurso hídrico, com a finalidade de irrigação e até mesmo de abastecimento público, como é realizado pelo departamento Autônomo de Água e Esgoto de Rio Claro (DAAE), que possui uma barragem no curso do Ribeirão Claro para atender 40,3\% da população rioclarense (FONSECA, 2008).

O Córrego Bandeirantes é afluente do Ribeirão Claro e sua nascente está localizada à $1500 \mathrm{~m}$ do Ribeirão Claro, englobando bairros Vila São Miguel, Conjunto Habitacional "Orestes Armando Giovanni" (Pé no Chão), Jardim Bandeirantes e Vila Nova (Figura 1), no município de Rio Claro, SP.

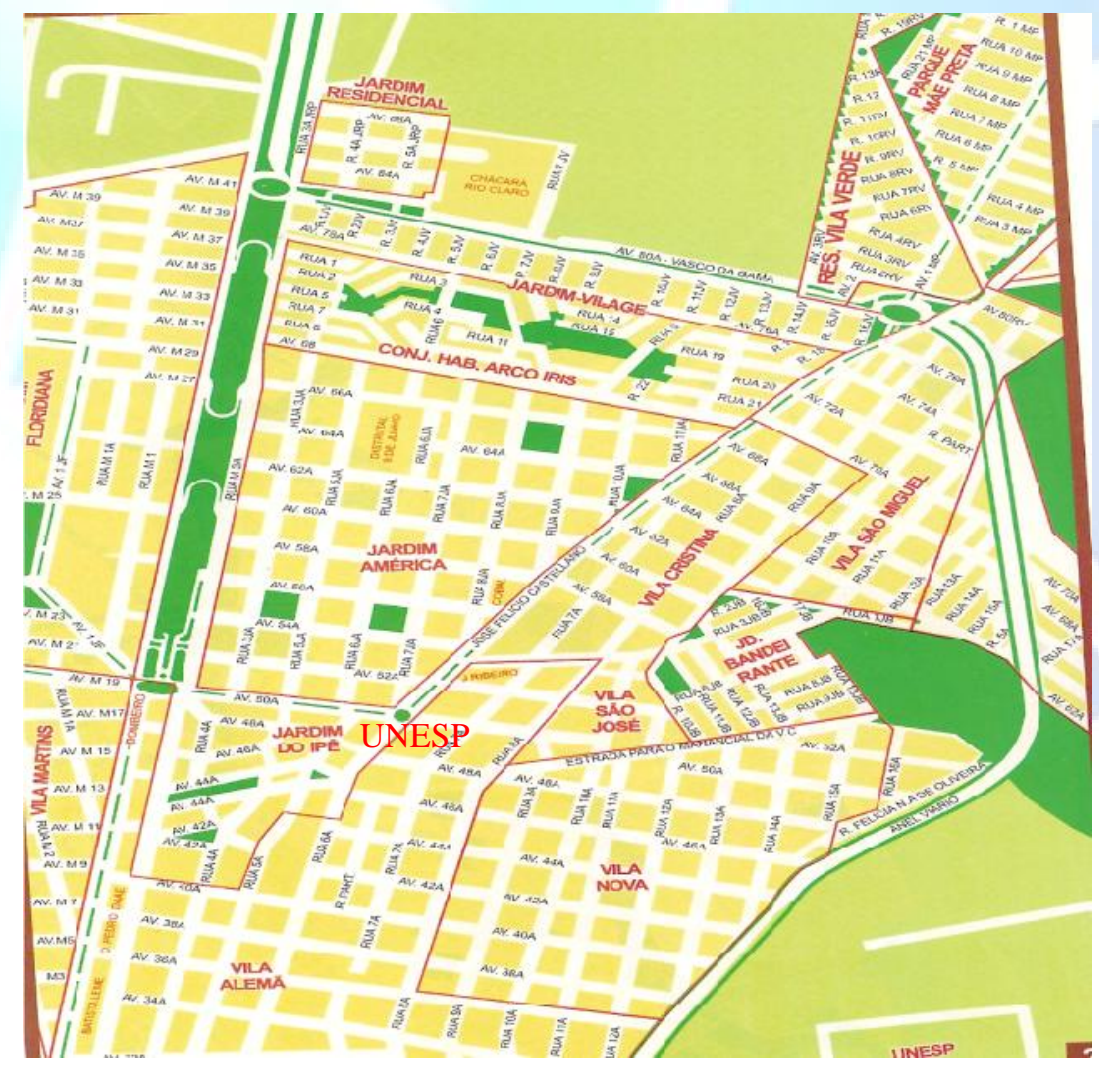

Figura 1. Localização dos bairros que engloba o Córrego Bandeirantes.

Fonte: Prefeitura Municipal de Rio Claro no estado de São Paulo - MAPA INDICE (2008). 


\section{MATERIAL E MÉTODOS}

Ao longo do Córrego Bandeirantes foram estudados três pontos para coletas de amostras de água, os mesmos utilizados por Canedo (2010) e Souza (2010), correspondendo ao da nascente P1 (UTM: 238013E km x 7522287N km), P2 (UTM: 238235E km x 7521922N km), P3 (UTM: $2390030,978 \mathrm{E} \mathrm{km} \mathrm{x} \mathrm{7521284,533N} \mathrm{km)} \mathrm{(Figura} \mathrm{2).} \mathrm{As} \mathrm{coletas} \mathrm{mensais} \mathrm{foram} \mathrm{realizadas} \mathrm{sempre} \mathrm{no}$ período da tarde, entre 14:00 e 15:00 horas, durante doze meses.

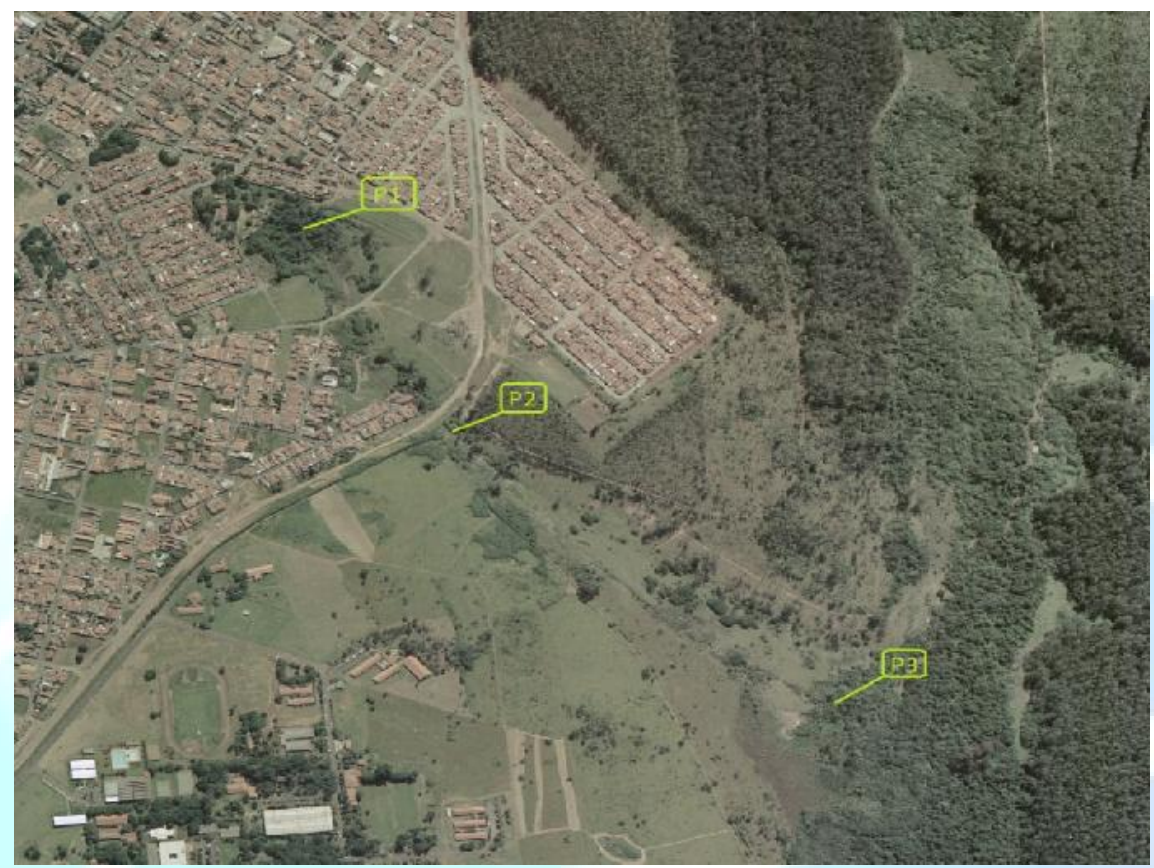

Figura 2. Localização dos pontos de coletas no Córrego Bandeirantes. Fonte: Base Aerofotogrametria e Projetos S. A. - Ceapla/IGCE/ UNESP- Rio Claro SP. Foto 1356283, escala 1:30000, 2006.

As amostras foram coletadas na metade do corte da calha principal do córrego, exceto na nascente, onde as coletas foram realizadas diretamente na mina. Estas amostras foram acondicionadas em frascos de polietileno de boca larga e tampa de rosca de $1 \mathrm{~L}$. Para as análises de coliformes totais e $E$. coli foram utilizados frascos de polietileno $250 \mathrm{~mL}$ esterilizados, sendo as tampas envoltas com papel protetor. As amostras foram acondicionadas em caixas térmicas com gelo e encaminhadas para o laboratório. Todos os procedimentos de coleta, transporte e armazenamentos foram seguidos de acordo com o Guia de Coleta e Preservação de Amostras (CETESB, 1987).

Foi realizada análise estatística dos resultados obtidos por meio da técnica de variância fatorial e da análise estatística multivariada representada pela Análise Componente Principal (Principal Component Analysis - PCA) para descrever o comportamento das variáveis químicas, físicas e microbiológicas realizadas no software STATISTICA 6.0.

As determinações dos fatores abióticos foram discutidas de acordo com os pontos de coletas e em relação aos períodos chuvoso/quente (outubro a março) e seco/frio (abril a setembro) correspondendo há 12 meses de estudo, utilizando modelo de variância do tipo fatorial. O Teste de Tukey foi aplicado quando a diferenças estatísticas foram significativas ao nível de $5 \%$ de significância, obtendo-se uma comparação múltipla entre os fatores analisados. 
A temperatura da água $\left({ }^{\circ} \mathrm{C}\right), \mathrm{pH}$, condutividade elétrica $\left(\mu \mathrm{S} . \mathrm{cm}^{-1}\right)$, sólidos totais dissolvidos $\left(\mathrm{mg} . \mathrm{L}^{-1}\right)$, oxigênio dissolvido $\left(\mathrm{mg} . \mathrm{L}^{-1}\right)$ foram determinados simultaneamente utilizando-se uma sonda com sistema multi-fatores marca YSI, modelo 556 MPS (Multi-ProbeSystem).

As determinações dos fatores abióticos foram discutidas de acordo com os pontos de coletas e em relação aos períodos chuvoso/quente (outubro a março) e seco/frio (abril a setembro) correspondendo há 12 meses de estudo, utilizando modelo de variância do tipo fatorial. $\mathrm{O}$ Teste de Tukey foi aplicado quando a diferenças estatísticas foram significativas ao nível de $5 \%$ de significância, obtendo-se uma comparação múltipla entre os fatores analisados.

A temperatura da água $\left({ }^{\circ} \mathrm{C}\right), \mathrm{pH}$, condutividade elétrica $\left(\mu \mathrm{S} \mathrm{cm}^{-1}\right)$, sólidos totais dissolvidos $\left(\mathrm{mg} . \mathrm{L}^{-1}\right)$, oxigênio dissolvido $\left(\mathrm{mg} . \mathrm{L}^{-1}\right)$ foram determinados simultaneamente utilizando-se uma sonda com sistema multi-fatores marca YSI, modelo 556 MPS (Multi-ProbeSystem).

As medidas de turbidez foram realizadas em laboratório utilizando o equipamento Turbidímetro Hach - modelo 2100P. O método de medida é a razão do sinal nefelométrico a $90^{\circ}$ desviado com a luz transmitida. A faixa de medição é de 0 a 1000 NTU com uma resolução de 0,01 NTU e precisão +/- 2\% da leitura mais o desvio de luz de 0-1000 NTU.

A determinação da demanda química do oxigênio foi realizada com a digestão ácida com dicromato de potássio, utilizando-se reator de digestão marca Hach, modelo Cod Reactor e espectrofotômetro marca Hach, modelo DR/2000 com precisão $\pm 1 \mathrm{mg} . \mathrm{L}^{-1}$.

A metodologia utilizada para o fator fósforo total foi de acordo com o método 4500-P do Standart Methods for the Examination of Water and Wastewater (APHA, 1998). Realizou-se digestão da amostra $(10 \mathrm{~mL})$ com solução saturada de persulfato de potássio em autoclave (30 min a $120{ }^{\circ} \mathrm{C}$ ). Após a digestão e resfriamento, adicionou-se reagente misto e procedeu-se à leitura em espectrofotômetro marca Cintra GBC UV - Visible a $880 \mathrm{~nm}$ de comprimento de onda.

O nitrogênio total foi medido usando-se o método de Mackereth et al. (1978), concentrandose $100 \mathrm{~mL}$ da amostra no bloco digestor marca Tecnal. Em seguida, a amostra foi destilada no destilador da marca Tecnal. O destilado foi capturado em ácido bórico $1 \%$ e titulado com ácido clorídrico $0,01 \mathrm{~N}$. As concentrações de nitrato, nitrito e nitrogênio amoniacal foram determinadas por meio do método 4500 Standard Methods for the Examination of Water and Wastewater (APHA, 1998). Utilizaram-se os Kits reagentes da marca Hach e as leituras foram realizadas em espectrofotômetro Hach, modelo DR/2000.

Os sólidos suspensos totais foram determinados com a filtração de $100 \mathrm{~mL}$ da amostra utilizando-se filtros da marca Whatmam $47 \mathrm{~mm}$ de diâmetro e $0,45 \mu \mathrm{m}$ de porosidade. Os filtros foram secos a $105^{\circ} \mathrm{C}$, por 24 horas e os resultados foram calculados com a formula:

$$
\mathrm{SS}\left(\mathrm{mg} \cdot \mathrm{L}^{-1}\right)=(\mathrm{mL}-\mathrm{mo}) .100 / \mathrm{va}
$$

Onde: SS: Sólidos em suspensão; mo: massa do filtro após secagem em estufa a $105{ }^{\circ} \mathrm{C}$ por $24 \mathrm{~h}$; mL: massa do filtro após filltração e secagem em estufa à $105{ }^{\circ} \mathrm{C}$ por $24 \mathrm{~h}$ e va: volume da amostra filtrada.

Para a determinação dos metais-traços foram filtradas $49 \mathrm{~mL}$ das amostras no sistema de filtração a vácuo de líquidos aquosos, Millipore, usando filtro 934-AH, Whatman, diâmetro 47mm e $0,45 \mu \mathrm{m}$ de porosidade e posteriormente acidificadas com ácido nítrico obtendo uma concentração final de $2 \%$. A leitura foi realizada em espectrofotômetro de emissão óptica simultânea com plasma acoplado indutivamente, marca THERMO, modelo iCAP 6.3000 Séries ICP.

Quanto aos fatores bióticos foram determinados a demanda bioquímica de oxigênio (DBO) e o de coliformes e Escherichia coli. Os organismos coliformes são definidos como bacilos gramnegativos, aeróbios ou anaeróbios facultativos, não formadores de esporos, que fermentam lactose com produção de ácido e gás em $24-48$ horas a $35{ }^{\circ} \mathrm{C}$. Neste grupo são incluídos: Escherichia, Citrobacter, Enterobacter e Klebsiella (SANCHEZ, 1999). As bactérias coliformes são facilmente 
isoladas da água e identificadas; as técnicas bacteriológicas para sua identificação são simples, além de rápidas e econômicas, o que permite sua aplicação em exames rotineiros para avaliação da qualidade bacteriológica da água.

Foi utilizada a técnica do substrato cromogênico hidrolisável para a detecção de coliformes totais e E. coli, metodologia descrita na Seção 9223B - Enzyme Substrate Coliform Test - Standard for the Examination of Water and Wastewater (APHA, 1998). O meio de cultura utilizado contém: ortho-nitrophenyl-D-galactopyranoside (ONPG) e o 4-thyl-umbelliferyl-D-gluconoride (MUG) que sofreram ação das enzimas D-galactosidase, produzida pelos coliformes totais e a D-glucuronidase produzida pela E.coli.

A hidrólise do ONPG em orthonitrophenol produz a cor amarela em 24 horas confirmando a presença de coliformes totais nas amostras e a hidrólise do MUG em methylumbelliferol produz fluorescência sob a incidência de radiação UV, confirmando a presença de E.coli na amostra.A poluição da água que vem ocorrendo ao longo dos anos é causada pelo desenvolvimento industrial, pelo crescimento demográfico e pela ocupação do solo de forma intensa e acelerada. Isto vem provocando o comprometimento dos recursos hídricos disponíveis para consumo humano, recreação e múltiplas atividades, aumentando consideravelmente o risco de doenças de transmissão e de origem hídrica (SANCHEZ, 1999).

Para a obtenção do NMP de coliformes totais e E. coli nas amostras de água, cada uma destas foram diluídas adequadamente, adicionando-se o conteúdo de um frasconete de Colilert em $100 \mathrm{~mL}$ da amostra. Este material foi homogeneizado e transferido para uma cartela Quanti-Tray com 97 células, que foi selada em uma seladora, marca IDEXX. Após a incubação em estufa a $35{ }^{\circ} \mathrm{C}$, por 24 horas, foram realizadas as leituras, verificando-se o número de células que apresentaram a cor amarela. Utilizando-se uma tabela específica foi determinado o Número Mais Provável (NMP) de coliformes totais por $100 \mathrm{~mL}^{-1}$ de amostra e por meio do número de células que apresentaram fluorescência sobincidência de luz UV, usando-se a mesma tabela, obteve-se o NMP de E.coli por $100 \mathrm{~mL}^{-1}$ da amostra.

Cálculo do Índice de Qualidade das Águas (IQA). CETESB (2002).

$$
\text { IQ } A=\prod_{i=1}^{n} q_{i}^{w_{i}}
$$

onde: IQA: Índice de Qualidade das Águas, um número entre 0 e 100; qi: qualidade do i-ésimo fator, um número entre 0 e 100 , obtido da respectiva "curva média de variação de qualidade", em função de sua concentração ou medida e wi: peso correspondente ao i-ésimo fator, um número entre 0 e 1, atribuído em função da sua importância para a conformação global de qualidade (Tabela 1) sendo que;

$$
\sum_{i=1}^{n} w_{i}=1
$$

Onde: n: número de fatores que entram no cálculo do IQA.

No caso de não se dispor do valor de algum dos nove fatores, o cálculo do IQA é inviabilizado. A partir do cálculo efetuado, pode-se determinar a qualidade das águas brutas, que é indicada pelo IQA, variando numa escala de 0 a 100 (Tabela 2). 
Tabela 1 - Peso dos fatores no cálculo do IQA. Fonte: CETESB (2002).

\begin{tabular}{l|l}
\hline \multicolumn{1}{c|}{ Fatores } & Peso $\left(w_{1}\right)$ \\
& \\
\hline Oxigênio dissolvido & 0,17 \\
E.coli & 0,15 \\
Ph & 0,10 \\
Demanda bioquímica de oxigênio & 0,10 \\
Nitrogênio total & 0,10 \\
Fósforo total & 0,10 \\
Temperatura & 0,10 \\
Turbidez & 0,08 \\
Sólidos totais & 0,08 \\
Somatória dos pesos dos fatores & $\mathbf{1 , 0}$ \\
\hline
\end{tabular}

Tabela 2 - Classificação das águas segundo IQA. Fonte: CETESB (2002).

\begin{tabular}{|c|c|}
\hline Categorias & Ponderação \\
\hline ÓTIMA & $79<\mathrm{IQA} \leq 100$ \\
\hline $\mathrm{BOA}$ & $51<\mathrm{IQA} \leq 79$ \\
\hline REGULAR & $36<\mathrm{IQA} \leq 51$ \\
\hline RUIM & $19<\mathrm{IQA}<36$ \\
\hline PÉSSIMA & IQA $\leq 19$ \\
\hline
\end{tabular}

\section{RESULTADOS E DISCUSSÃO}

\subsection{Temperaturas da água e do ar}

A temperatura da água $\left({ }^{\circ} \mathrm{C}\right)$ durante um ano de estudo variou entre 21,4 a $26,7{ }^{\circ} \mathrm{C}$ ao longo da cava principal do córrego Bandeirantes. No período seco/frio, o valor médio mínimo foi de $23,3{ }^{\circ} \mathrm{C}$ e o maior de $24,0^{\circ} \mathrm{C}$, sendo que no período úmido/chuvoso foram, respectivamente, de $25,1^{\circ} \mathrm{C}$ e $26,2^{\circ} \mathrm{C}$.

A análise da variância fatorial dos resultados demonstrou que para o fator período de estudo, ao nível de 5\% de significância, foi encontrada diferença entre os períodos chuvoso/quente e seco/frio, onde no primeiro foi observada a maior média de temperatura da água, o que já era esperado. Organismos aquáticos possuem limites de tolerância térmica superior e inferior, temperaturas ótimas para crescimento e preferidas em gradientes térmicos e limitações das mesmas para migração, desova e incubação de ovos (CETESB, 2009). O tempo gasto para a realização das coletas, aproximadamente uma hora, não foi suficiente para ocorrer mudanças na temperatura do ar nos pontos amostrados.

Os organismos aquáticos possuem limites de tolerância térmica superior e inferior, temperaturas ótimas para crescimento, temperatura preferencial em gradientes térmicos e limitações de temperatura para migração. Variações de temperatura são partes do regime climático normal e corpos de água naturais apresentam variações sazonais e diurnas, bem como estratificação vertical.

\section{2. $\mathrm{pH}$}

A análise da variância fatorial mostrou que para o fator pontos de coletas, ao nível de $5 \%$ de significância, houve diferenças estatisticamente significativas quanto aos valores de $\mathrm{pH}$. Aplicandose o Teste de Tukey, verificou-se que as diferenças foram estatisticamente significativas, sendo que o maior valor encontrado foi no ponto de coleta de amostras P3. 
O menor valor encontrado foi no mês de abril no ponto de coleta P1 e o maior foi 7,7 em julho no P3. A Resolução CONAMA 357/2005 (BRASIL, 2005) estabeleceu que para os corpos hídricos de águas doces, o pH deve estar entre os limites de 6,0 e 9,0. Valores de pH abaixo de 6.0 foram encontrados em todos os pontos revelando o caráter ácido das águas deste corpo hídrico, portanto, fora do limite para rios de classe 2. Perez (2002) reportou valores de $\mathrm{pH} 4,8$ na nascente e também 6,1 na foz do córrego Bandeirantes.

A complexidade e a importância na interpretação dos valores de $\mathrm{pH}$ da água são influenciadas pelas concentrações de seus valores e pelo grande número de fatores que podem influenciá-los. Muitas reações químicas que ocorrem no ambiente são intensamente afetadas pelo valor de $\mathrm{pH}$. Sistemas biológicos também são sensíveis a estes, sendo que, usualmente, o meio deve ter $\mathrm{pH}$ entre 6,5 e 8,5 para que os organismos não sofram danos (MORAIS, 2010).

\subsection{Condutividade elétrica}

A condutividade elétrica é a capacidade que a água possui de conduzir corrente elétrica. Os sais dissolvidos e ionizados presentes nela transformam-na em um eletrólito capaz de conduzir a corrente elétrica. Como há uma relação da proporcionalidade entre o teor de sais dissolvidos e a condutividade elétrica pode-se estimar o teor de sais pela medida de condutividade de uma água. Quanto maior for a quantidade de íons dissolvidos, maior será a condutividade elétrica na água (CETESB, 2002).

As médias dos valores da condutividade elétrica em cada ponto de coletas no período seco/frio foram de $99 \mu \mathrm{S} . \mathrm{cm}^{-1} 1$ a $130 \mu \mathrm{S} . \mathrm{cm}^{-1}$ e no período chuvoso/quente de $100 \mu \mathrm{S} . \mathrm{cm}^{-1} 1$ a 190 $\mu \mathrm{S} . \mathrm{cm}^{-1}$. A análise de variância fatorial para a variável dependente condutividade elétrica demonstrou que quanto ao ponto de coletas e ao período de estudo houve diferenças estatisticamente a 5\% de significância. Os menores valores foram encontrados no ponto P1 entre 80 e $97 \mu \mathrm{S} . \mathrm{cm}^{-1}$, com exceção em fevereiro cujo valor foi de $189 \mu \mathrm{S} . \mathrm{cm}^{-1}$.

Nos demais pontos, estes foram maiores. Destaca-se o aumento significativo observado nos pontos de coletas P2 e P3 em janeiro de 2011. No período de estudo ocorreu um rompimento na rede de esgoto resultando uma descarga de lançamento de esgoto no Córrego Bandeirantes. No período chuvoso/quente foi observada maior média para condutividade elétrica decorrente do carreamento de íons para dentro da cava principal do rio, devido à má conservação de suas margens e do uso e ocupação do solo ao seu redor. Fonseca (2008), estudando o Ribeirão Claro e seus afluentes, encontrou valores de condutividade elétrica que variaram de $46 \mu \mathrm{S} . \mathrm{cm}^{-1}$ e $766 \mu \mathrm{S} . \mathrm{cm}^{-1}$. Sendo notável o impacto degradante dos diversos pontos de lançamento de esgoto doméstico sobre a qualidade da água do Ribeirão Claro.

\subsection{Sólidos totais dissolvidos (STD)}

Os resultados para o fator STD encontrados revelaram que as médias referentes ao período seco/frio foram de 60 a $90 \mathrm{mg} . \mathrm{L}^{-1}$ e no período chuvoso/quente entre 65 a $190 \mathrm{mg} . \mathrm{L}^{-1}$. A análise de variância demonstrou que os dois fatores analisados pontos de coletas e período de estudo não apresentaram diferenças estatisticamente significativas, pois ambos os casos $\mathrm{p}>0,05 \%$. A Resolução CONAMA 357/2005 (BRASIL, 2005) estabeleceu um limite máximo de 500 mg.L ${ }^{-1}$ para os corpos hídricos de classe 2, quanto aos valores de sólidos totais. Verificou-se valor superior a esse limite no ponto de coletas P2 no mês de janeiro de 2011, como resultado de descarga de efluentes ocorrido nesse período. Os sólidos podem também reter bactérias e resíduos orgânicos no fundo dos rios, promovendo decomposição anaeróbia (MATTOS, 1999).

\subsection{Oxigênio dissolvido (OD)}

Os resultados para o fator OD nas águas do córrego Bandeirantes mostraram que as médias referentes ao período seco/frio foram de 5,5 a 5,9 mg. $\mathrm{L}^{-1}$ e no período chuvoso/quente entre 
5,9 mg. $\mathrm{L}^{-1}$ a $8,3 \mathrm{mg} \cdot \mathrm{L}^{-1}$. A análise da variância fatorial para a variável dependente oxigênio dissolvido demonstrou que em relação aos pontos de coletas das amostras de água no córrego Bandeirantes e aos períodos de estudo não houve diferenças estatisticamente significativas, em nível de significância de $\mathrm{p}>0,05 \%$

O decréscimo de OD nas águas do Córrego Bandeirantes foi observado em todos os pontos no mês de julho e nos pontos P2 e P3 em janeiro. Analisando a média obtida deste com base na Resolução CONAMA 357/2005 (BRASIL, 2005) pode-se classificar o Córrego Bandeirantes dentro da classe 2, considerando o limite mínimo de $5 \mathrm{mg} \cdot \mathrm{L}^{-1}$.

\subsection{Turbidez(UNT)}

As médias de turbidez das águas do córrego Bandeirantes nos pontos de coletas variaram no período seco/frio de 0,0 a 9,0 UNT e no período chuvoso/quente entre 0,0 a 20,0 UNT. A análise de variância do fator turbidez demonstrou que em relação aos pontos de coletas e aos períodos de estudo não houve diferenças estatisticamente significativas, para ambos os casos a $p>0,05 \%$. Nas diferentes amostras de água coletadas nos distintos pontos de coletas e nos dois períodos de estudo não foi verificado nenhum valor de turbidez abaixo do limite definido pela Resolução CONAMA 357/2005 (BRASIL, 2005) para corpos hídricos de classe 2, ou seja, 100 UNT.

\subsection{Cor aparente (Units PtCo.)}

$\mathrm{Na}$ água, a cor pode ser de origem mineral ou vegetal causada por substâncias metálicas como ferro ou manganês, matérias húmicas, taninos, algas, plantas aquáticas e protozoários, ou por resíduos orgânicos ou inorgânicos de indústrias, como as refinarias, explosivos, polpa de papel, substâncias químicas e outras (BATTALHA e PARLATORE, 1977). As águas naturais possuem cor que varia entre 0 e 200 unidades, pois com maiores valores já seriam águas de brejo ou de pântano com altos teores de matéria orgânica dissolvida. Coloração abaixo de 10 unidades é quase imperceptível (MORAIS, 2010).

As médias em cada ponto de coletas no período seco/frio variaram de 0,0 a $25,0 \mathrm{mgPtCo.L^{-1 }}$ e no período chuvoso/quente entre 0,0 a $150,0 \mathrm{mgPtCo}^{-1} \mathrm{~L}^{-1}$ A análise de variância para este fator demonstrou que os dois fatores analisados pontos de coletas e período de estudo não apresentaram diferenças estatisticamente significativas, ambos os casos a $\mathrm{p}>0,05 \%$. Maior intensidade das cores foi observada nos pontos de coletas P2 e P3 no mês janeiro. Segundo a Resolução CONAMA 357/2005 (BRASIL, 2005), o limite máximo permitido para rios das classes 2 e 3 são de 75 (mg PtCo.L $\left.\mathrm{L}^{-1}\right)$.

\subsection{Demanda química de oxigênio DQO $\left(\mathrm{mg}^{-\mathrm{L}^{-1}}\right)$}

As médias de DQO em cada ponto de coletas no período seco/frio variaram entre 0,0 a 19,5 mg. $\mathrm{L}^{-1}$ e no período chuvoso/quente entre 0,0 a $30,0 \mathrm{mg} . \mathrm{L}^{-1}$. Somente quanto aos pontos de coletas houve diferenças estatisticamente significativas, em nível de 5\% de significância, sendo realizado o Teste de Tukey para este fator, verificando-se que para o período de estudo não se verificou diferença estatisticamente significativa. Os maiores valores de DQO foram observados nos pontos de coletas P2 e P3 em janeiro de 2011, fato este não observado em outros períodos de estudo.

$\mathrm{O}$ rompimento da rede de esgoto ocorrido neste período próximo à microbacia do Córrego Bandeirantes, segundo a foz do BRASIL, Rio Claro, SP acarretou aumento dos valores da DQO e de todos outros fatores analisados nesse período. Observou-se ainda no local, efeitos crônicos e ofensivos dos odores resultantes da descarga do esgoto lançado na microbacia. Verifica-se que a DQO no Córrego Bandeirantes apresentou valores variando entre $<1 \mathrm{mg} . \mathrm{L}^{-1}$ e $134 \mathrm{mg} . \mathrm{L}^{-1}$. Esses valores são superiores aqueles obtidos por Palma-Silva (2006), no rio Corumbataí (<1 mg.L.' e 101 mg. $\left.\mathrm{L}^{-1}\right)$. 


\subsection{Fósforo total ( $\mu$ g. $\left.\mathrm{L}^{-\mathbf{1}}\right)$}

As fontes artificiais de fósforo mais importantes são: esgotos domésticos e industriais, fertilizantes agrícolas, águas residuárias de criação de animais e material particulado de origem industrial contido na atmosfera (ELIAS, 2003).

As médias de fósforo em cada ponto de coleta no período seco/frio variaram entre 50,0 a 140,0 $\mu \mathrm{g} . \mathrm{L}^{-1}$ e no período chuvoso/quente entre 50,5 a 80,0 $\mu \mathrm{g} . \mathrm{L}^{-} 1$. A análise de variância para o fator fósforo total demonstrou que os dois fatores analisados pontos de coletas e período de estudo não apresentaram diferenças estatisticamente significativas, pois ambos os casos p>0,05 \%. A Resolução do CONAMA 357/205 (BRASIL, 2005) estabeleceu o limite de $100 \mu \mathrm{g} . \mathrm{L}^{-1}$ para ambiente lótico e tributário de ambiente intermediários pertencentes à classe 2. Valores acima deste estabelecido pela Resolução foram observados nos pontos P1 $\left(404,00 \mu \mathrm{g} . \mathrm{L}^{-1}\right)$, P2 $\left(198,00 \mu \mathrm{g} . \mathrm{L}^{1}\right)$, e P3 (198,00 $\left.\mu \mathrm{g} . \mathrm{L}^{-1}\right)$ em março de 2010; no P1 $\left(281,00 \mu \mathrm{g} . \mathrm{L}^{-1}\right), \mathrm{P} 2\left(253,00 \mu \mathrm{g} . \mathrm{L}^{-1}\right)$, e P3 $(256,00$ $\left.\mu \mathrm{g} . \mathrm{L}^{-1}\right)$ em abril de 2010; no P2 (156 $\mu$ g.L $\left.\mathrm{L}^{-1}\right)$, em julho de 2010; no P2 (136,00 $\mu$ g.L $\left.\mathrm{L}^{-1}\right)$, em agosto de 2010; no P2 (1477,87 $\left.\mu \mathrm{g} . \mathrm{L}^{-1}\right)$, e P3 $\left(1160,29 \mu \mathrm{g} . \mathrm{L}^{-1}\right)$ em janeiro de 2011.

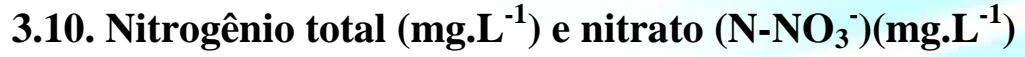

As médias de nitrogênio no período seco/frio variaram entre 1,2 e $2,1 \mathrm{mg} . \mathrm{L}^{-1}$ e no período chuvoso/quente entre 3,0 a 6,0 mg. $\mathrm{L}^{-1}$. Ao nível de 5\% de significância, o fator período de estudo apresentou diferenças estatísticas significativas, sendo que o Teste de Tukey demonstrou que para o fator de amostragem não houve diferenças estatisticamente significativas. O ponto $\mathrm{P} 2$ apresentou as maiores médias para ambos os períodos estudados. As maiores médias deste fator ocorreram no período chuvoso/quente, podendo este fato estar relacionado com o escoamento superficial mais intenso característico deste período.

O nitrato é a forma mais oxidada do nitrogênio. Provavelmente, é o ânion mais estável nas condições existentes nas águas superficiais. Devido ao alto estado de oxidação, o nitrato é quimicamente estável e pode ser alterado mediante processos de transformações e consumo biológico. Segundo Kadlec (1996), o nitrato é também um nutriente essencial para o crescimento da biomassa, e em excesso conduz o processo de eutrofização dos corpos de água. Ele é uma variável importante a ser monitorada em programas de controle das águas, devido a sua toxidade, principalmente para as crianças, causando uma doença chamada de metemoglobinemia. A concentração máxima de nitrato permitido pelo Ministério da Saúde, em água destinadas ao abastecimento público é de $10 \mathrm{mg} . \mathrm{L}^{-1}$.

As médias de nitrato em cada ponto de coletas no período seco/frio variaram entre 1,0 a 1,7 mg. $\mathrm{L}^{-1}$ e no período chuvoso/quente entre 2,0 e $3,9 \mathrm{mg} . \mathrm{L}^{-1}$. Ao nível de $5 \%$ de significância, o fator período de estudo apresentou diferenças estatísticas significativas, sendo que os resultados do Teste de Tukey demonstraram que o fator de amostragem não foi diferente estatisticamente. O íon nitrato é altamente solúvel e a forma mais estável do nitrogênio combinado em águas superficiais (TAUKTORNISIELO e PALMA-SILVA, 2008). Os períodos seco/frio e chuvoso/quente diferenciaram entre si, indicando que as altas pluviosidades podem contribuir para introdução de nitrato nas águas.

Segundo a Resolução CONAMA 357/2005 (BRASIL, 2005) os valores máximos recomendados de nitrato deverão ser $10,0 \mathrm{mg} . \mathrm{L}^{-1}$ para as águas de classe 2 . No Ribeirão Claro as concentrações de nitrato foram inferiores a este limite, em média menores de $1 \mathrm{mg} . \mathrm{L}^{-1}$ (FONSECA, 2008). Palma-Silva (2006) estudando o rio Corumbataí obteve valores de nitrato entre 0,4 e 3,4 mg.L ${ }^{1}$, sugerindo que os efluentes industriais e esgotos domésticos, especialmente esgoto, também contém estes sais, podendo estar contribuindo para o acréscimo nos corpos de água localizados na bacia do rio Corumbataí.



As médias dos valores de nitrito no período seco/frio variaram entre 0,0 a $0,2 \mathrm{mg} . \mathrm{L}^{-1}$ e no período chuvoso/quente entre 0,0 a $0,05 \mathrm{mg} . \mathrm{L}^{-1}$. A análise de variância para este fator demonstrou 
que os dois fatores analisados, pontos de coletas e período de estudo não apresentaram diferenças estatisticamente significativas, pois em ambos os casos $\mathrm{p}>0,05 \%$. Quando presente na água de consumo humano tem efeito mais rápido e pronunciado do que o nitrato. A cloração com residuais de cloro livre converte o nitrito a nitrato (BATTALHA e PARLATORE, 1977). A Resolução CONAMA 357/2005 (BRASIL, 2005) estabeleceu limites deste fator para rios de classe 2 em 1,0 $\mathrm{mg} . \mathrm{L}^{-1}$, sendo que para o período de estudo não se observaram valores acima deste.

As médias em cada ponto de coleta no período seco/frio variaram entre 0,0 e $0,2 \mathrm{mg} . \mathrm{L}^{-1}$ e no período chuvoso/quente entre 0,0 e $2,4 \mathrm{mg} . \mathrm{L}^{-1}$, para o fator amônia. A análise de variância para este fator demonstrou que os dois fatores analisados, pontos de coletas e período de estudo não apresentaram diferenças estatisticamente significativas, pois em ambos os casos $\mathrm{p}>0,05 \%$. Os valores de amônia encontrados nos pontos P2 (15,20 mg. $\left.\mathrm{L}^{-1}\right)$ e P3 (12,40 mg. $\left.\mathrm{L}^{-1}\right)$, em janeiro de 2011 foram superiores ao limite permitido pela Resolução CONAMA 357/2005 (Brasil, 2005), que estabeleceu um limite máximo de 3,7 mg.. $\mathrm{L}^{-1}$, para $\mathrm{pH} \leq 7,5$.

A amônia representa a forma primária do nitrogênio logo após a degradação dos compostos nitrogenados, componentes e aminoácidos, sendo oxidada a nitrito e posteriormente a nitrato. Dessa forma a sua presença permite identificar fontes orgânicas poluidoras recentes (MORAIS, 2010). Os maiores valores observados nos pontos de coletas P2 e P3 no mês de janeiro podem indicar fontes orgânicas poluidoras próximas a tais pontos.

\subsection{Sólidos suspensos totais ( $\left.\mathrm{mg}^{-\mathrm{L}^{-1}}\right)$}

As médias deste fator no período seco/frio variaram entre 0,0 e $19,0 \mathrm{mg} . \mathrm{L}^{-1}$ e no período chuvoso/quente entre 4,0 e 39,2 mg.L $\mathrm{L}^{-1}$. A análise de variância para este fator demonstrou que os dois fatores analisados, pontos de coletas e período de estudo, não apresentaram diferenças estatisticamente significativas, pois em ambos os casos $\mathrm{p}>0,05 \%$. Alterações nos valores deste fator foram detectados nos pontos P2 (132,4 mg. $\left.\mathrm{L}^{-1}\right)$ e P3 $\left(138,7 \mathrm{mg} . \mathrm{L}^{-1}\right)$, em janeiro, decorrente do lançamento de esgoto doméstico observado neste período de coleta.

\subsection{Metais - traço cádmio $\left(\mu g . \mathrm{L}^{-1}\right)$, cobre $\left(\mu \mathrm{g} . \mathrm{L}^{-1}\right)$, níquel $\left(\mu \mathrm{g} . \mathrm{L}^{-1}\right)$, chumbo $\left(\mu \mathrm{g} . \mathrm{L}^{-1}\right)$ e $\operatorname{zinco}\left(\mu \mathrm{g} . \mathrm{L}^{-1}\right)$.}

Poluentes que penetram no ambiente aquático podem se associar ao sedimento do fundo, onde permanecem, a não ser que ocorram perturbações, como no processo de dragagem, onde eles voltam para os corpos de água e tornam-se biologicamente ativos. As águas do Córrego Bandeirantes apresentaram valores inferiores a $1 \mu \mathrm{g} . \mathrm{L}^{-1}$ de cádmio, portanto não atingindo a sensibilidade do método analítico utilizado, valores inferiores ao que a Resolução CONAMA $357 / 2005$ (BRASIL, 2005) fixou como padrão, isto é, limite de até $1 \mu \mathrm{g} . \mathrm{L}^{-1}$ para os rios de classe 1 e 2 .

As médias de cobre no período seco/frio variaram entre 5,0 e $8,2 \mathrm{mg} . \mathrm{L}^{-1}$ e no período chuvoso/quente entre 1,0 e 3,0 mg. $\mathrm{L}^{-1}$ nos pontos de coletas. Ao nível de $5 \%$ de significância, o fator período de estudo apresentou diferenças estatísticas significativas, sendo que os resultados do Teste de Tukey demonstraram que para o fator de amostragem não houve diferenças. O cobre está geralmente em pequenas quantidades nas águas superficiais e subterrâneas. Na forma de cloreto, sulfato e nitrato são muitos solúveis na água, não acontecendo o mesmo quando se apresenta como carbonato, hidróxido, óxido e sulfeto. Os íons de cobre, que se encontram em pH igual ou maior do que 7 nas águas naturais, precipitam o carbonato e hidróxido e são assim removíveis por adsorção ou sedimentação. Este é o motivo pelo qual não se encontram concentrações significativas de cobre nas águas superficiais ou subterrâneas (BATTALHA e PARLATORE, 1977).

As principais formas solúveis de cobre encontradas na água doce e salgada são $\mathrm{Cu}^{2+}, \mathrm{Cu}$ $\left(\mathrm{HCO}_{3}\right)$ e $\mathrm{Cu}\left(\mathrm{OH}_{2}\right)$. Em valores de $\mathrm{pH}$ e concentrações de carbonato características de águas naturais, a maior parte do $\mathrm{Cu}$ (II) dissolvido acha-se, preponderantemente, na forma de complexos e 
não como íon cúprico livre. A maior parte do cobre liberado para cursos de água se encontra como material particulado, o qual é precipitado ou adsorvido à matéria orgânica, ao ferro hidratado, aos óxidos de manganês e depositado em sedimentos ou colunas e corpos da água (AZEVEDO e CHASIN, 2003).

Os resultados aqui encontrados revelaram que os teores mais expressivos de cobre foram detectados nos pontos P2 (12,44 $\mu$ g.L $\left.\mathrm{L}^{-1}\right)$, abril de 2010; P2 (11,11 $\left.\mu \mathrm{g} . \mathrm{L}^{-1}\right)$, maio de 2010; P3 (13,41 $\left.\mu \mathrm{g} . \mathrm{L}^{-1}\right)$, junho de 2010 e P2 $\left(12,75 \mu \mathrm{g} . \mathrm{L}^{-1}\right)$, de janeiro de 2011. Os maiores valores para o Cu foram encontrados no período seco/frio. A Resolução CONAMA 357/2005 (BRASIL, 2005) fixou o limite de $9 \mu \mathrm{g} . \mathrm{L}^{1}$ para os rios de classe 2 .

As médias de níquel no período seco/frio não variaram ficando em $0,0 \mu \mathrm{g}$. $\mathrm{L}^{-1}$ e no período chuvoso/quente variaram nos pontos de coletas entre 0,0 a $6,0 \mu \mathrm{g} . \mathrm{L}^{-1}$. Ao nível de $5 \%$ de significância, o fator período de estudo apresentou diferenças estatísticas significativas, sendo os resultados do Teste de Tukey demonstraram que para o fator de amostragem não houve diferenças estatisticamente significativas. Nenhum valor encontrado para os pontos de coletas foi superior aquele estabelecido como limite máximo pela Resolução CONAMA 357/2005 (BRASIL, 2005) para rios de classe 2, ou seja, $25 \mu \mathrm{g} . \mathrm{L}^{-1}$. Verificou-se que os maiores valores para o $\mathrm{Ni}$ foram encontrados no período de chuvoso.

A maior parte do níquel ocorre com o ferro magnésio, mineral de rochas metamórficas e ígneas. As concentrações de níquel em mananciais são geralmente menores do que $2-10 \mu \mathrm{g} . \mathrm{L}^{-1}$.No ser humano, a maior parte do níquel ingerido na alimentação não é absorvida, apresentando meiavida em torno de 11 horas, sendo eliminado nas fezes de $158 \pm 75 \mu \mathrm{g} / \mathrm{dia}$ (AZEVEDO e CHASIN, 2003).

O chumbo foi detectado apenas um ponto P2 (7,56 $\left.\mu \mathrm{g} . \mathrm{L}^{-1}\right)$, em junho de 2010. Não foram encontrados nas outras amostras provavelmente ficando seus valores abaixo da sensibilidade da metodologia utilizada. A Resolução CONAMA 357/2005 (BRASIL, 2005) estabeleceu limite deste fator para rios das classes 1 e 2 de $10 \mu \mathrm{g} . \mathrm{L}^{-1}$.

$\mathrm{Na}$ água, o metal se divide rapidamente entre o sedimento e a fase aquosa, dependendo do pH da mesma e dos sais nela dissolvidos, além da presença de agentes complexantes orgânicos. Observou-se que em $\mathrm{pH}>5,4$, a solubilidade total do chumbo é de, aproximadamente, $30 \mu \mathrm{g} . \mathrm{L}^{-1} \mathrm{em}$ águas duras (com alto teor de cálcio dissolvido) e de, aproximadamente, $500 \mu \mathrm{g} . \mathrm{L}^{-1} \mathrm{em}$ águas moles (baixo teor de cálcio). O escoamento superficial urbano e a deposição atmosférica são fontes significativas indiretas do chumbo encontrado em ambientes aquáticos (AZEVEDO e CHASIN, 2003).

As médias de zinco para cada ponto de coleta variaram no período seco/frio entre 20,0 a $38,0 \mu \mathrm{g} . \mathrm{L}^{1}$ e no período chuvoso/quente entre 20,0 a 36,0 $\mu \mathrm{g} . \mathrm{L}^{1}$. A análise de variância para este fator demonstrou que os dois fatores analisados, pontos de coletas e período de estudo, não apresentaram diferenças estatisticamente significativas, em ambos os casos $p>0,05 \%$. Nenhum valor encontrado para os pontos de coletas foram superiores a $180 \mu \mathrm{g} . \mathrm{L}^{-1}$, valor estabelecido como limite máximo pela Resolução CONAMA 357/2005 (BRASIL, 2005) para as classes 1 e 2.

No rio Cabeça, Morais (2010) também encontrou valores abaixo do padrão em todos os pontos desse corpo hídrico. Mas ao contrário, no rio Corumbataí, Tauk-Tornisielo et al. (2008) verificaram concentrações superiores ao limite padrão, obtendo valores de $\mathrm{Zn}$ de até $550 \mu \mathrm{g} . \mathrm{L}^{1}$.

\subsection{Fatores bióticos}

Os níveis de $\mathrm{DBO}_{5}$ no Córrego Bandeirantes se encontram na tabela 20. As médias da $\mathrm{DBO}_{5}$ para o período seco/frio variaram 4,0 a $22,0 \mathrm{mg} . \mathrm{L}^{-1}$ e no período chuvoso/quente entre 10,0 a 30,0 mg. $\mathrm{L}^{-1}$, nos pontos de coletas. A análise de variância para demanda bioquímica de oxigênio demonstrou que os dois fatores analisados, pontos de coletas e período de estudo, não apresentaram diferenças estatisticamente significativas, pois ambos os casos $\mathrm{p}>0,05 \%$. 
A DBO é a determinação da quantidade de oxigênio consumido durante a degradação da matéria orgânica biodegradável por um período de tempo de 5 dias, em uma temperatura de incubação de $20{ }^{\circ} \mathrm{C}$. Os maiores aumentos da DBO em um corpo de água são acarretados por despejos de origem predominante orgânica. A presença de um alto teor de matéria orgânica pode induzir a um desequilíbrio da vida aquática. (CETESB, 2002).

Os níveis da $\mathrm{DBO}_{5}$ no Córrego Bandeirantes variam entre $\mathrm{P} 1,<1 \mathrm{mg} . \mathrm{L}^{-1} \mathrm{e} \quad 18,9 \mathrm{mg} . \mathrm{L}^{-1}$;

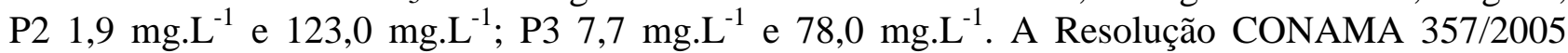
(BRASIL, 2005) para classes 1 e 2 estabeleceu limites para este fator que não deve ultrapassar $5 \mathrm{mg} . \mathrm{L}^{-1}$. Dessa forma, os resultados obtidos no Córrego Bandeirantes no período estudado não se enquadram na classe 2 podendo estes corpos hídricos ser reenquadrados na classe 3 cujo limite é de $10 \mathrm{mg} . \mathrm{L}^{-1}$ ou até classe 4 acima desse valor.

A $\mathrm{DBO}_{5}$ é importante como um teste quantitativo das condições de um curso de água poluída, mas não deve ser supervalorizada. Deve ser um indicador do comprometimento das condições do meio, mas não deve ser tomada como elemento de valor absoluto na determinação da qualidade e, menos ainda, da potabilidade da água.

Outro fator biológico determinado foi o de Coliformes totais e Escherichia coli (NMP $100 \mathrm{~mL}^{-1}$ ). No período seco/frio não houve variação no número de coliformes totais e no período chuvoso/quente os valores médios deste fator variaram entre 0,0 e $4 \mathrm{E} 7 \mathrm{NMP} .100 \mathrm{~mL}^{-1}$. A análise de variância para coliformes totais demonstrou que os dois fatores analisados, pontos de coletas e período de estudo, não apresentaram diferenças estatisticamente significativas, pois ambos os casos p>0,05\%. Considerando a vigência da Resolução CONAMA 357/2005 (BRASIL, 2005) este fator não foi estabelecido limites. Em todos os pontos de coletas, os maiores valores obtidos foram detectados nos pontos P2 (2117 x 10 $\left..100 \mathrm{~mL}^{-1}\right), \mathrm{P} 3\left(1937 \times 10^{5} .100 \mathrm{~mL}^{-1}\right)$, em janeiro de 2011.

As médias dos valores de Escherichia coli nos pontos de coleta no período seco/frio não variaram e no período chuvoso/quente ficaram entre 0,0 e 1,5 E6 NMP.100 $\mathrm{mL}^{-1}$. A análise de variância para Escherichia coli demonstrou que os dois fatores analisados, pontos de coletas e período de estudo, também não apresentaram diferenças estatisticamente significativas, pois ambos os casos tiveram $\mathrm{p}>0,05 \%$.

A Resolução CONAMA 357/2005 (BRASIL, 2005) estabeleceu limites para corpos de água classes 1 e 2 , sendo o valor de até 1000 E. coli por $100 \mathrm{~mL}$ em $80 \%$ ou mais de pelo menos seis amostras coletadas durante o período de um ano, com frequência bimestral. Todos os resultados encontrados nos pontos de coletas P2 e P3 situaram acima da legislação excetuando o ponto de coletas P1.

Estudos realizados por Perez (2002) reportaram que somente na nascente do Córrego Bandeirantes o valor de E. coli foi inferior ao valor recomendado pela Resolução CONAMA 357/05 (BRASIL, 2005). Comparando-se esses resultados com aqueles aqui encontrados, pode ser observado que em todos os pontos de coletas ocorreu um aumento do valor desta variável de 2002 até 2011. As médias encontradas nos anos de 2002 foram, respectivamente, de P1 28,6 NMP.100 $\mathrm{mL}^{-1}$; P2 $31000 \mathrm{NMP} .100 \mathrm{~mL}^{-1}$ e P3 $28700 \mathrm{NMP} .100 \mathrm{~mL}^{-1}$, também muito acima do limite estabelecido para rios de classe 2, pela Resolução supracitada.

\subsection{5. Índice de Qualidade da Água (IQA)}

Os resultados para o IQA nos diferentes pontos de coletas no córrego Bandeirantes no período de estudo de março de 2010 a fevereiro de 2011 demonstraram variações entre 17 e 68 (Figuras 3 e 4). Os resultados no ponto P1 variam de 28 a 68, sendo que em $25 \%$ dos casos a água foi classificada como boa, $16,6 \%$ regular e 58,4\% ruim. No ponto P2 variaram de 17 a 60 , sendo que em $25 \%$ dos casos foram classificadas como boa, 58,4\% regular, 8,3\% ruim e 8,3\% péssima.

Os resultados obtidos no P3, os valores foram entre 18 a 56, sendo que em $25 \%$ dos casos foram classificada boa, $66,7 \%$ regular e $8,3 \%$ péssima. Levando em consideração todos os pontos 
de coletas e o período de estudo, o Córrego Bandeirantes apresentou água de qualidade boa (26\%), qualidade regular $(45 \%)$, qualidade ruim $(23 \%)$ e qualidade péssima $(6 \%)$. Ocorreu uma grande variação de IQA entre os meses estudados. Essa variação se deu, principalmente, nos fatores coliformes fecais e DBO, ambas associadas ao lançamento dos esgotos neste corpo hídrico.
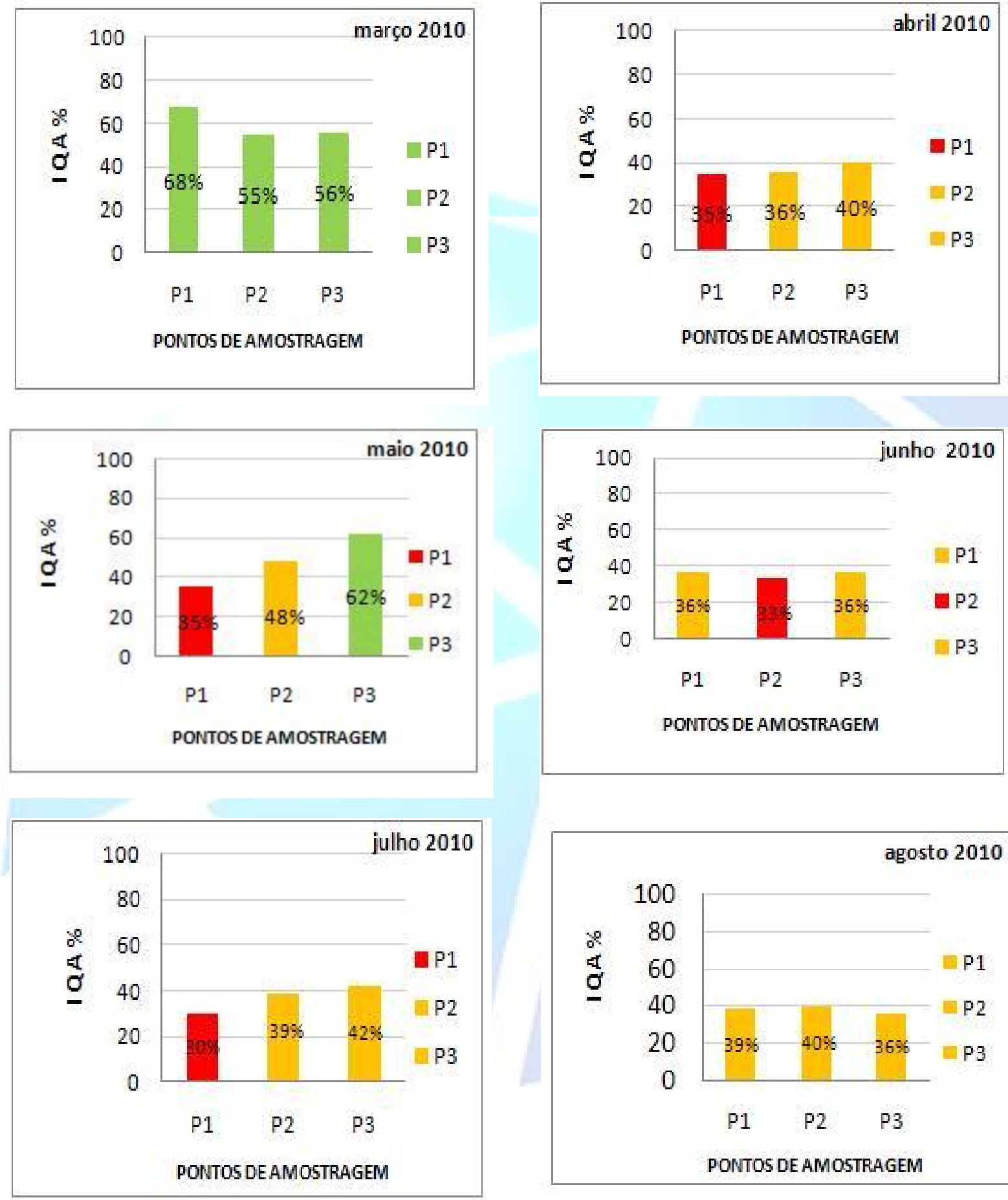

Legenda:

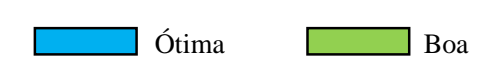

Regular
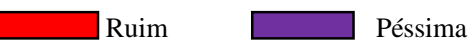

Figura 3. Índice de qualidade da água (IQA) determinado nos pontos de coletas de água no Córrego Bandeirantes nos períodos de março de 2010 a agosto de 2010. Fonte: Elaborado pelos autores. 

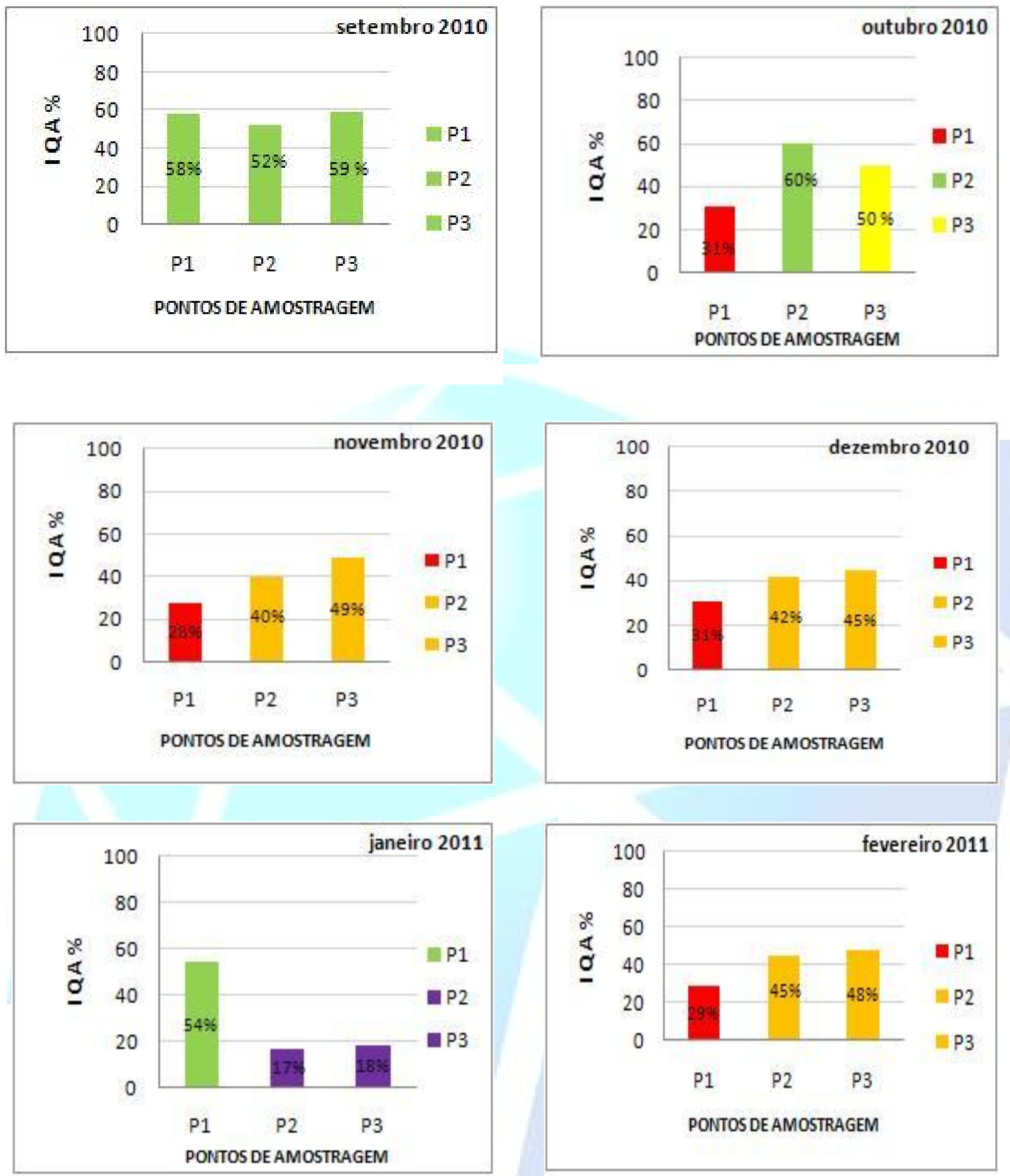

Legenda:
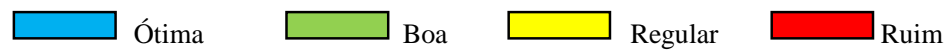

Péssima

Figura 4. Índice de qualidade da água (IQA) determinado nos pontos de coletas de água no Córrego Bandeirantes nos períodos de setembro de 2010 a fevereiro de 2011. Fonte: Elaborado pelos autores. 


\section{CONCLUSÕES}

Dentre os fatores presentes na água do Córrego Bandeirantes, município de Rio Claro, SP, temperatura, condutividade elétrica, nitrogênio total, nitrato, $\mathrm{Cu}$ e $\mathrm{Ni}$ possuem valores significativamente diferentes estatisticamente quanto aos períodos chuvoso/quente e seco/frio.

Todos os valores de metais-traço $\mathrm{Cd}, \mathrm{Cu}, \mathrm{Ni}, \mathrm{Pb}$ e $\mathrm{Zn}$ estiveram abaixo do limite máximo estabelecido pela Resolução CONAMA 357/2005 para rio de classe 2.

A maioria dos valores de DBO e Escherichia coli encontrado para o Córrego Bandeirantes estiveram acima do limite estabelecido pela Resolução CONAMA 357/2005 para rio de classe 2, desclassificando-o da mesma;

A qualidade da água do córrego Bandeirantes foi classificada como regular, segundo o Índice de Qualidade da Água (IQA) desenvolvido pela CETESB.

Considerando que os resultados apresentados neste trabalho são referentes a apenas 1 (um) ano, o que é considerado um período relativamente curto em se tratando de estudos hidrológicos, faz-se necessário dar prosseguimento a estes estudos. Com a implantação de dois quilômetros e meio de emissários de esgoto construídos recentemente e a construção de outros sete quilômetros, justifica o acompanhamento dos fatores nesta microbacia.

Ficou evidenciada a necessidade de maior conscientização da importância de um recurso hídrico e que sem o envolvimento participativo da comunidade de entorno, fica inviável qualquer atividade para melhoria da área da microbacia do Córrego Bandeirantes.

\section{REFERÊNCIAS}

APHA - AMERICAN PUBLIC HEALTH ASSOCIATION. Standart Methods for the Examination of Water and Wastewater. 20 ed. Washington: American Public Health Association, AWWA, WPCF, 1998. 1569 p.

AZEVEDO, F.A.; CHASIN, A.A.M. Metais: gerenciamento da toxidade. [S.I] Atheneu, 2003. $554 \mathrm{p}$.

BATALHA, B.L.; PARLATORE, A.C. Controle da qualidade da água para consumo humano: bases conceituais e operacionais. São Paulo: CESTESB, 1977. 198 p.

BRASIL. Conselho Nacional do Meio Ambiente. Resolução do CONAMA no 357 . Brasília: MMA, 2005. 23 p.

CANEDO, S.N. Diagnóstico Ambiental no Período frio e Seco do Córrego Bandeirantes, Município de Rio Claro, SP. Fatores físicos, químicos e físico-químicos. 2010. 31 f. Trabalho de Conclusão (Bacharelado - Engenharia Ambiental) - Instituto de Geociências e Ciências Exatas, Universidade Estadual Paulista, Rio Claro, 2010.

CERRI, M.S. Proposta Metodológica para o Estudo de Microbacias Hidrográficas Urbanizadas: O Exemplo do Córrego Lavapés, Rio Claro, SP. 1999. 174 f. Dissertação (Mestrado em Conservação e Manejo de Recursos, Área de Concentração Gestão Integrada de Recursos) - Centro de Estudos Ambientais, Universidade Estadual Paulista, Rio Claro, 1999. 
CETESB - COMPANHIA DE TECNOLOGIA E SANEAMENTO AMBIENTAL. Relatório de qualidade das águas interiores do estado de São Paulo 2008. São Paulo: CETESB, p.528, 2009.

DERISIO, J.C. Introdução ao controle de poluição ambiental. São Paulo: CETESB, 1992. 201p.

ELIAS, J.M. Análise da eficiência global do sistema de "Wetlands" construído na estação de tratamento de água para abastecimento público no município de Analândia. 2003. 214 f. Dissertação (Mestrado em Conservação e Manejo de Recursos, Área de Concentração Gestão Integrada de Recursos) - Centro de Estudos Ambientais, Universidade Estadual Paulista, Rio Claro, 1999.

FONSECA, W.C. Ajuste do modelo Qual2K e simulação de cenários para o Ribeirão Claro. 2008. 51 f. Trabalho de Conclusão de Curso (Bacharelado - Engenharia Ambiental) - Instituto de Geociências e Ciências Exatas, Universidade Estadual Paulista, Rio Claro, 2008.

KADLEC, R.H. Na auto biotic wetland phosphorus removal model. Ecological Enginering, Oxiford, v. 8, n. 2, 1996, p. 145-172.

MAPAINDICE. Divisão geográfica de Rio Claro. Departamento de sistemas e análise de informação municipal de Rio Claro SEPLADEMA/atualização cartográfica - 2008.

MATTOS, M.Y.H.G. Análise temporal da qualidade da água em um trecho do rio Sorocaba e de seus afluentes Ipanema e Pirajibu, e comparação com a legislação ambiental vigente. 1999. 117 f. Dissertação (Mestrado em Geociências e Meio Ambiente) - Instituto de Geociências e Ciências Exatas, Universidade Estadual Paulista, Rio Claro, 1999.

MORAIS, E.B. Indicadores Microbiológicos, Metais-traços e índice de qualidade da água (IQA) do rio Cabeça, na bacia do rio Corumbataí, SP. 2010. 139 f. Tese (Doutorado em Ciências Biológicas Área de Concentração de Microbiologia Aplicada) - Instituto de Biociências do Campus de Rio Claro, Universidade Estadual Paulista Rio Claro, 2010.

PALMA-SILVA, G.M. Redação dos indicadores microbiológicos com outros fatores liminológicos no Rio Corumbataí, SP, no intuito de propor um modelo matemático para gestão ambiental. 2006. 174 f. Tese (Doutorado em Ciências Biológicas, Área de Concentração Microbiológica Aplicada) - Instituto de Biociências, Universidade Estadual Paulista, Rio Claro, 2006.

PALMA-SILVA, G.M.; TAUK-TORNISIELO, S.M. Contribuición de lãs áreas urbanas e La polución del rio de Corumbataí, SP, Brazil. In: Contribución a La educación y La proteccion ambiental v.2, vII Taller, p.1-9, 2001.

PEREZ, P.M. Verificação da Qualidade Sanitária da Água do Córrego Bandeirante - Afluente do Ribeirão Claro mediante análises físicas, químicas e microbiológicas. 2002. 68 f. Trabalho de Conclusão de Curso, (Bacharelado em Biologia) - Instituto de Biociências, Universidade Estadual Paulista, Rio Claro, 2002.

RICHTER, C.A, NETTO, J.M.A. Tratamento de água: tecnologia atualizada. São Paulo: Edgar Blucher, 1991. 330p. 
SANCHEZ, P.S. Atualização em técnicas para o controle microbiológico de águas minerais. São Paulo, 1999. 125 f. (Apostila da Universidade Mackenzie) - Pós Graduação em Ciências Ambientais, Universidade Mackenzie, São Paulo, 1999.

SOUZA, D.L. Diagnóstico Ambiental do Córrego Bandeirantes, município de Rio Claro, SP. Fatores Biológicos e Metais-traço. 2010. 37 f. Trabalho de Conclusão de Curso (Bacharelado em Engenharia Ambiental) - Instituto de Geociências e Ciências Exatas, Universidade Estadual Paulista, Rio Claro, 2010.

TAUK-TORNISIELO, S.M.; PALMA-SILVA, G.M. Qualidade das águas. In: TAUKTORNISIELO, S.M.; ESQUEIRO, J.C. Bacia do Rio Corumbataí - aspectos socioeconômicos e ambientais. Piracicaba, Consórcio PCJ, 2008. p. 59-84.

VALENTE, R.O.A. Análise da estrutura da paisagem na bacia do rio Corumbataí, SP. 2001. 144 f. Dissertação (Mestrado em Recursos Florestais, Área de Concentração em Conservação de Ecossistemas Florestais) - Escola Superior de Agricultura Luiz de Queiroz, Universidade de São Paulo, Piracicaba, 2001.

WALLING, D.E.; GREGORY, K.J. Drainage basin form and process: a geomorphologic approach. London: Edward Arnold, 1973. 456 p. 